\title{
The accumulation of sugars and organic acids in blackberry fruit in the conditions of Central Russia
}

\author{
Margarita Makarkina, , Lidia Gruner, Oksana Vetrova, and Daria Matnasarova \\ Russian Research Institute of Fruit Crop Breeding (VNIISPK), Orel district, 302030, Ghilina, Orel \\ Orel region, Russian Federation
}

\begin{abstract}
The taste characteristics of berries of 26 cultivars, elite and selected forms of blackberries grown in Central Russia are presented: dry matter, monosaccharides, sucrose acid the total amount of sugars. The sugar-acid index has been calculated. The best genotypes have been identified according to the content of dry matter and sugars - Brzezina and Agawam cultivars, elite seedlings LN-4, LN-13, LN-14 and selected seedlings LN-5, LN-7, LN-8, according to the content of organic (titrated) acids and sugaracid index - Brzezina, Black Satin, Loch Tau, seedlings of Black Satin, Cheyenne, Loch Ness - LN-6, LN-10, EV LN-13 and control cultivar Agawam. A high traits' conjugation was established: the sugar-acid index and the content of monosaccharides, the total amount of sugars, soluble solids, as well as a high inverse dependency between the content of organic acids and the sugar-acid index. Low unreliable correlation coefficients $(\mathrm{r}=$ $-0.28 \ldots+0.13$ ) were obtained, indicating the absence of links between the fruit weight and the content of biochemical components responsible for the taste characteristics of genotypes, which is a positive fact when creating new cultivars with high taste and a significant weight of fruits, indicating their independent inheritance.
\end{abstract}

\section{Introduction}

Currently, the Earth's population is exposed to negative environmental influences: polluted drinking water and air, low sanitary conditions, etc. The fast-paced lifestyle of a significant number of people leads to unhealthy diets, fast foods and other products with the use of fats and flavor enhancers. Nevertheless, the preservation of health and life expectancy based on a healthy lifestyle come out on top among a significant part of the population of the Russian Federation. This is largely facilitated by good nutrition, based on the consumption of natural nutrients and biologically active substances contained in fruits and berries in sufficient quantities.

The crop that has attracted the interest of the population of Russia in recent years is blackberry. It is popular and widely known in the world. During the period of 1995-2005, the global area of blackberry production increased by $44 \%$ [1]. The main producers of

\footnotetext{
*Corresponding author: makarkina@vniispk.ru
} 
blackberries are the USA (over 3,500 ha) and Europe - Serbia (over 5,000 ha). Recently, the state of Chile has become the supplier of blackberries for processing [2].

Growing blackberries in Central Russia is limited by the relatively low frost resistance of the aboveground part of plants, which is overpassed with the use of new technologies for growing this crop based on winter cover $[3,4,5]$. This deficiency is offset by the excellent specific taste of blackberries and their rich biochemical composition. At the same time, blackberry is a cost-effective crop. Foreign experience in its cultivation evidences the rapidly growing volume of production, which brings good income due to the high yield and high selling price of berries. Blackberries begin fruiting one year after planting, which allows to quickly recoup the investments [6]. But the expanding market of berry products is tightening the requirements for the creation of new cultivars, including the quality of fruits and their biochemical composition [7, 8].

First of all, blackberries contain substances that determine their taste characteristics of various genotypes. These are sugars and titratable acids; their quantity and ratio in combination with aromatic components are responsible for the taste of berries. In addition, ascorbic acid, phenolic compounds (anthocyanins, ellagic acid, catechins and other flavonoids), pectin substances with high antioxidant activity, macronutrients, amino acids, etc. are found in blackberries. Depending on the cultivar and growing conditions, blackberry fruits contain $5.1-13 \%$ of sugars (glucose, fructose), $0.5-1.5 \%$ of organic acids (malic, citric, salicylic, tartaric, etc.), up to $1.8 \%$ of pectin substances, fiber - from 2 to $4 \%$, vitamin C (ascorbic acid), B, P groups (phenolic compounds) (700-1000 mg/100 g), E, carotene, tannins; mineral elements - potassium, sodium , calcium (up to $200 \mathrm{mg} / 100 \mathrm{~g}$ ), magnesium, phosphorus (up to $240 \mathrm{mg} / 100 \mathrm{~g}$ ), iron (up to $10 \mathrm{mg} / 100 \mathrm{~g}$ ), etc. $[9,10,11,12$, 13].

The purpose of this research was to study blackberry cultivars of the gene pool of the Russian Research Institute of Fruit Crop Breeding (VNIISPK) by the content of soluble dry matter, sugars, organic acids and the value of the sugar-acid index as indicators of the taste characteristics of various genotypes and the selection of the best ones to be used in breeding to improve the quality of fruits.

\section{Materials and methods}

The objects of the study were 26 blackberry cultivars from the VNIISPK gene pool, including 15 selected and elite seedlings of the VNIISPK selection: selected seedlings of Black Satin, Cheyenne cultivars from open pollination, elite (ES) and selected seedlings (LN) of the Loch Ness cultivar. The content of soluble dry matter (Brix), sugars (mono-, disaccharides and their sum), organic acids w/ere determined in blackberries, and the sugaracid index (SAI) was calculated. Sampling was carried out at the site for the cultivar study of blackberries, biochemical analyzes were carried out in the laboratory of biochemical and technological assessment of cultivars and storage at the VNIISPK. In this research, generally accepted methods were used [14, 15]: fruits were taken for analysis at the moment of their full maturity (method based on the ability of reducing sugars were determined with a free carboxyl group to $\mathrm{r} 0.5 \mathrm{~kg}$ ), soluble dry matter (SDM) (Brix, \%) were determined by the refractometric method using a digital refractometer PAL-3 (ATAGO); sugars - by the Be educe copper oxide in an alkaline solution to protoxidic one; organic acids (titratable acidity) - by titrating certain volumes of extract with $0.1 \mathrm{~N}$ sodium hydroxide solution in the presence of phenolphthalein indicator; the determination of the sugar acid index (SAI) (Ratio) was calculated as the ratio of the total sugar content to the organic acid content. Statistical processing of research results was carried out using the analysis package of Microsoft Excel and STATISTICA 6.0. The coefficients of variation $(\mathrm{V} \%)$ and the error of mean $(\mathrm{m})$ were calculated considering three-year data. 


\section{Results and discussion}

The main indicators that determine the taste of fruits are sugars and organic acids, as well as their ratio - the sugar-acid index (Ratio). According to the literary data $[16,17,18]$ based on the study of the chemical composition of the fruits of other crops, SDM (Brix) and sugars, which make up most of the SDM, are in close correlation. Brix is an indirect indicator that determines the sugar content of fruits and berries, which allows, with a large experimental material, to quickly and accurately select high-sugar genotypes.

Studies of the biochemical composition of blackberry fruits carried out over four years (2017-2020) are summarized and presented in Table 1.

Table 1. Characteristics of blackberry genotypes in terms of sugar acid indicators and fruit wright (2017-2020).

\begin{tabular}{|c|c|c|c|c|c|c|c|}
\hline \multirow{2}{*}{$\begin{array}{l}\text { Cultivar, } \\
\text { selected } \\
\text { seedling }\end{array}$} & \multirow[b]{2}{*}{$\begin{array}{c}\text { Berry } \\
\text { weight, } g\end{array}$} & \multirow{2}{*}{$\begin{array}{c}\text { SDM } \\
\text { (Brix), } \\
\%\end{array}$} & \multicolumn{3}{|c|}{ Sugar, \% } & \multirow{2}{*}{$\begin{array}{c}\text { Titratabl } \\
\text { e acidity, } \\
\%\end{array}$} & \multirow[t]{2}{*}{ SAI } \\
\hline & & & $\begin{array}{c}\text { monosacc } \\
\text { haride }\end{array}$ & sucrose & sum & & \\
\hline Agawam - c. & 2,6 & 12,7 & 8,76 & 1,32 & 10,08 & 0,61 & 16,5 \\
\hline Brzezina & 7,6 & 14,2 & 10,94 & 0,44 & 11,38 & 0,88 & 12,9 \\
\hline Black Satin & 4,6 & 12,3 & 8,56 & 0,66 & 9,22 & 0,82 & 11,2 \\
\hline $\begin{array}{l}\text { Cacanska } \\
\text { Bestrna }\end{array}$ & 5,2 & 12,1 & 8,36 & 0,54 & 8,90 & 0,99 & 9,0 \\
\hline Chester & 7,7 & 11,4 & 7,53 & 0,54 & 8,07 & 1,00 & 8,1 \\
\hline Erie & 3,6 & 11,7 & 8,24 & 0,64 & 8,88 & 1,16 & 7,7 \\
\hline Loch Tay & 5,5 & 12,7 & 10,54 & 0,42 & 10,96 & 0,77 & 14,2 \\
\hline Natchez & 12,9 & 10,8 & 8,11 & 0,30 & 8,41 & 1,14 & 7,4 \\
\hline Ouachita & 6,9 & 11,7 & 8,15 & 0,80 & 8,95 & 1,02 & 8,8 \\
\hline Texas & 4,4 & 11,6 & 8,06 & 0,58 & 8,64 & 1,99 & 4,3 \\
\hline Thornfree - c. & 5,6 & 11,2 & 8,48 & 0,72 & 9,20 & 0,95 & 9,7 \\
\hline Triple Crown & 7,7 & 11,2 & 7,59 & 0,40 & 7,99 & 1,10 & 7,3 \\
\hline $\begin{array}{ll}\text { Seedl. } & \text { Black } \\
\text { Satin } & \end{array}$ & 4,1 & 11,6 & 9,27 & 0,24 & 9,51 & 0,77 & 12,4 \\
\hline Seedl. Cheyenne & 4,3 & 13,2 & 9,39 & 0,52 & 9,91 & 0,77 & 12,9 \\
\hline Seedl. LN * -1 & 3,6 & 11,6 & 7,12 & 0,50 & 7,62 & 0,95 & 8,0 \\
\hline Seedl. LN-2 & 3,0 & 13,8 & 9,03 & 0,63 & 9,66 & 1,13 & 8,5 \\
\hline Seedl. LN-3 & 3,6 & 12,8 & 9,34 & 0,23 & 9,57 & 1,07 & 8,9 \\
\hline Seedl. LN-4 EV & 5,9 & 13,9 & 9,57 & 0,62 & 10,19 & 0,96 & 10,6 \\
\hline Seedl. LN-5 & 2,8 & 14,8 & 10,40 & 0,20 & 10,60 & 1,02 & 10,4 \\
\hline Seedl. LN-6 & 3,4 & 11,9 & 8,08 & 0,38 & 8,46 & 0,80 & 10,6 \\
\hline Seedl. LN-7 & 3,4 & 14,4 & 10,49 & 0,61 & 11,10 & 1,04 & 10,7 \\
\hline Seedl. LN-8 & 3,2 & 12,7 & 9,31 & 0,73 & 10,04 & 1,03 & 9,7 \\
\hline Seedl. LN-9 & 2,3 & 11,3 & 7,33 & 0,16 & 7,49 & 1,03 & 7,3 \\
\hline Seedl. LN-10 & 4,1 & 10,4 & 8,34 & 0,67 & 9,01 & 0,70 & 12,9 \\
\hline Seedl. LN-12 & 4,0 & 11,2 & 8,49 & 0,99 & 9,48 & 0,99 & 9,6 \\
\hline $\begin{array}{ll}\text { Seedl. } & \text { LN-13 } \\
\text { EV } & \end{array}$ & 3,8 & 12,4 & 11,25 & 0,07 & 11,32 & 0,62 & 18,3 \\
\hline $\begin{array}{ll}\text { Seedl. } & \text { LN-14 } \\
\text { EV } & \end{array}$ & 4,4 & 13,3 & 9,43 & 0,99 & 10,42 & 0,99 & 10,5 \\
\hline Average, $\bar{x}$ & 4,8 & 12,3 & 8,92 & 0,55 & 9,47 & 0,97 & 10,4 \\
\hline Error, $m$ & 0,4 & 0,2 & 0,22 & 0,06 & 0,22 & 0,05 & 0,6 \\
\hline Minimum & 2,3 & 10,4 & 7,12 & 0,07 & 7,49 & 0,61 & 4,3 \\
\hline Maximum & 12,9 & 14,8 & 11,25 & 1,32 & 11,38 & 1,99 & 18,3 \\
\hline
\end{tabular}




\begin{tabular}{|c|c|c|c|c|c|c|c|}
\hline $\begin{array}{l}\text { Variation } \\
\text { coefficient, } \quad V, \\
\%\end{array}$ & 47,3 & 9,6 & 12,6 & 51,3 & 11,7 & 26,6 & 29,4 \\
\hline
\end{tabular}

Note: * - LN - seedling of Loch Ness variety.

With the average value of SDM in fruits for all studied cultivars equal to $12.3 \pm 0.2 \%$, the genotypes with an indicator exceeding this level ( $\mathrm{SDM}>12.5 \%)$ were distinguished: Loch Tay, Seedl. LN-2, EV LN -4, Seedl. LN-5, Seedl. LN-7, Seedl. LN-8, EV LN-14 and the control cultivar Agawam. In the bulk of the cultivar samples (70\%), the SDM content in the fruits was below the average value. The range of variation depending on the cultivar varied from 10.4 to $14.8 \%$, the coefficient of variation was $9.6 \%$, which indicated a weak varietal variability of the studied trait.

The average content of the total sugars in the fruits of the studied blackberries was $9.47 \%$ with a range of variation from $7.49 \%$ (Seedl. LN-9) to $11.38 \%$ (Brzezina). Of the total amount of sugars, $94 \%$ were monosaccharides (glucose + fructose) and only $6 \%$ were sucrose. The cultivar variability of (Table 2$)$, the value of which $(r=+$ this indicator was average $(\mathrm{V}=11.7 \%)$. Brzezina and Agawam, as well as elite seedlings LN-4, LN-13, LN14 and selected seedlings LN-5, LN-7, LN-8 accumulated sugars in fruits above the average value $(>10.00 \%)$. The genotypes isolated by the sugar content in fruits practically coincided with the previously isolated cultivars in terms of the SDM content, which was confirmed in the above-mentioned literary sources and the correlation coefficient calculated by us $0.82^{* * *}$ ) indicated high positive reliable connection between these two biochemical traits. We have found that the amount of monosaccharides is closely related to the sum of sugars and SAI - the correlation coefficients are $0.97 * * *$ and $0.74 * * *$, respectively.

Table 2. Correlation coefficients ( $\mathrm{r}$ ) between indicators of the chemical composition of blackberry fruits.

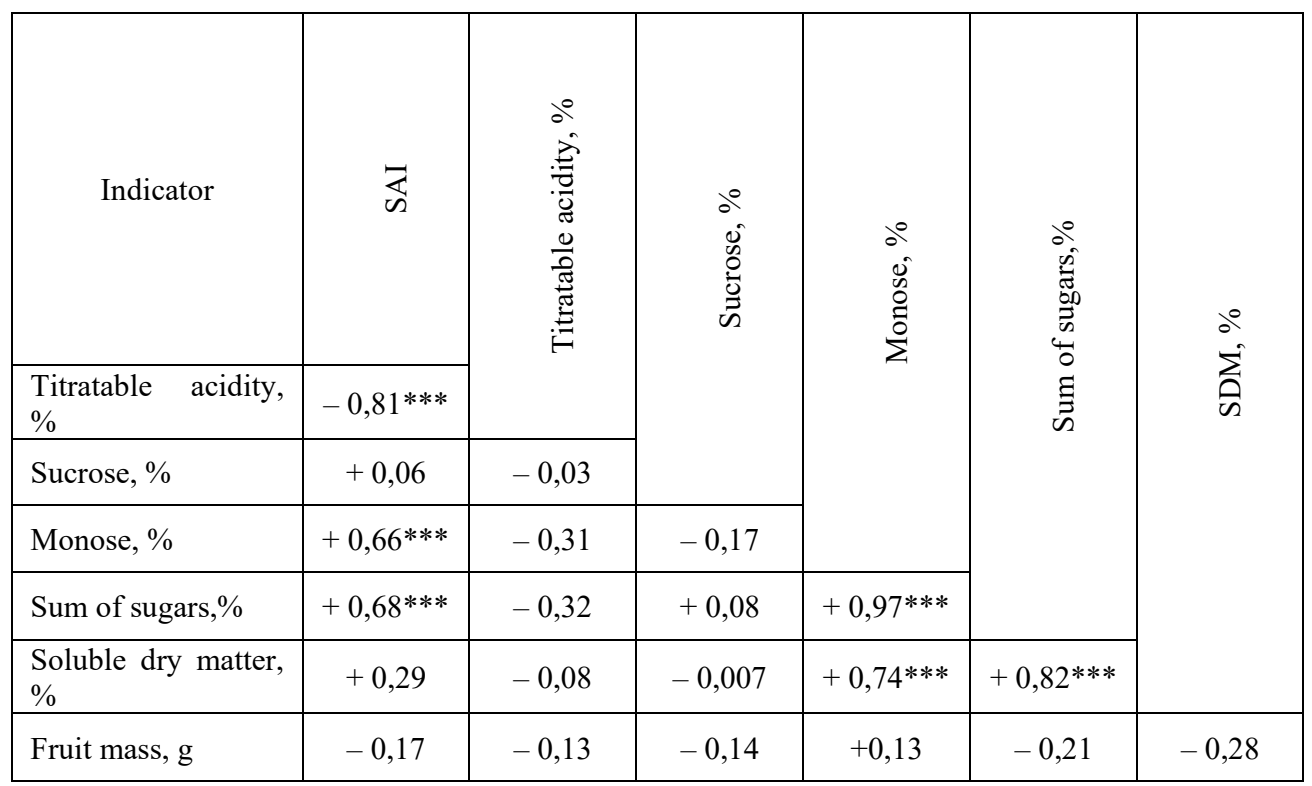

Organic (titratable) acids in the fruits of berry crops are mainly represented by citric acid; therefore, the titratable acidity in the fruits of the studied cultivars of blackberries was recalculated using citric acid. Depending on the genotype, the content of organic acids varied from 0.61 (Agawam) to $1.99 \%$ (Texas) with a high coefficient of variation (V = $26.6 \%$ ) and an average value of $0.97 \%$. Organic acids affect the taste of fruits more than 
sugars. This is confirmed by the correlation coefficients (Table 2). There is a high inverse relationship between the content of organic acids in fruits and the sugar acid index $(\mathrm{r}=-$ $0.81 * * *)$, between the sugar acid index, the total amount of sugars $(\mathrm{r}=+0.68 * * *)$ and the content of monosaccharides $\left(\mathrm{r}=+0.66^{* * *}\right)$ - high straight line. Moreover, when comparing the absolute values, the correlation coefficient between SAI and titratable acidity was higher. SAI varied significantly - from 4.3 (Texas) to 18.3 (EV LN-13).

Brzezina, Black Satin, Loch Tay, seedlings of Black Satin, Cheyenne, Loch Ness - LN6, LN-10, EV LN-13 and the control cultivar Agawam were distinguished by low titratable acidity $(<0.90 \%)$ of fruits and high SAI value $(>11.0)$; with an average content of organic acids (0.90-1.10\%) - Chester, Ouachita, Triple Crown, elite seedlings LN-4, LN-14, selected seedlings LN-1, LN-3, LN-5, LN-7, LN-8, LN-9, LN-12 and the control cultivar Thornfree. The third group included cultivars with a relatively high titratable acidity (c> $1.10 \%)$ and a low SAI value $(<7.5)$ of fruits: Natchez and Texas. All studied cultivars have a pleasant fruit taste and can be used as dessert ones. But conditionally they can be divided in this way: the first group of cultivars is for baby food, the second is for dessert purposes for the adult population, and the third is for processing.

The fruit mass of the studied genotypes does not affect the content of the studied biochemical components responsible for their taste characteristics, which is a positive fact when creating new cultivars with high taste properties and a significant fruit weight, as evidenced by low unreliable correlation coefficients $(\mathrm{r}=-0.28 \ldots+0.13)$.

\section{Conclusions}

As a result of studying the biochemical components of blackberry fruits of the VNIISPK gene pool, which are responsible for taste characteristics, the best genotypes were identified: according to the content of SDM and sugars - Brzezina and Agawam, elite seedlings LN-4, LN-13, LN-14 and selected seedlings LN-5, LN-7, LN-8 with insignificant varietal variability; by the content of organic (titratable) acids and SAI - Brzezina, Black Satin, Loch Tau, seedlings of Black Satin, Cheyenne, Loch Ness varieties - LN-6, LN-10, ELS LN-13 and the control cultivar Agawam.

A high trait conjugation was established: the sugar-acid index and the content of monosaccharides, the total amount of sugars, soluble dry matter, as well as a high inverse dependency between the content of organic acids and the sugar-acid index. Low unreliable correlation coefficients $(r=-0.28 \ldots+0.13)$ were identified, indicating the absence of links between the fruit weight and the content of biochemical components responsible for the taste characteristics of genotypes, which is a positive fact when creating new cs with high taste and a significant mass of fruits, indicating their independent inheritance.

\section{References}

1. B.C. Strik, Proceeding of the IXth international Rubus and Ribes symposium 777, 403410 (2008) https://doi.org/10.17660/ActaHortic. 2008.777.61

2. J.R Clark., C.E. Finn, Revista Brasileira de Fruticultura, 36 (1), $46-57$ (2014). https://doi.org/10.1590/0100-2945-445/13

3. F. Takeda, D.A. Handley, HortScience $41 \quad$ (4), 1011 (2006) https://doi.org/10.21273/HORTSCI.41.4.1011D

4. F. Takeda, D.M. Glenn, T.J. Tworkoski, Berry Res 3, 25-40. (2013) DOI:10.3233/JBR130044

5. L.A. Gruner, O.V. Kulesheva, Contemporary horticulture 3 (15), 10-16 (2015) 
6. J.R. Clark, C.E. Finn, Rev. Bras. Frutic $36 \quad$ (1), 46-57 (2014) https://doi.org/10.1590/0100-2945-445/13

7. J.R. Clark, C.E. Finn, Global Science Books (Fruit, Vegetable and Cereal Science and Biotechnology), 5, 27-43 (2011) UR https://www.researchgate.net/publication/2892 12567_Blackberry_breeding_and_genetics

8. L.A. Gruner, B.B. Kornilov, Vavilovsky Journal of Genetics and Breeding. 24 (5), 489-500 (2020) https://doi.org: 10.18699 / VJ20.641

9. L.A. Gruner, A.P. Anikeenko, Selection and cultivation of horticultural crops, 266-273. (1995)

10. A.M. Connor, C.E. Finn, P.A. Alspach, Am. Soc. Hortic. Sci. 130 (4). 527-533. (2005) https://doi.org/10.21273/JASHS.130.4.527

11. A.L. Khodakov, D.V. Ermolin, G.V. Ermolina, G.P. Zaitsev, V.A. Vinogradov, Food Science and Technology, 3 (16), 40-42. (2011)

12. L. Ali, B.W. Alsanius, A.K. Rosberg, B. Svensson, T. Nielsen, M.E. Eur Food Rec Technol, 234, 33-44. (2012) DOI:10.1007/s00217-011-1604-8

13. T. Milošević, N. Milošević, I. Glišić., J. Mladenović, Plant, Soil Environ, 58 (7), 322327 (2012) https://doi.org/10.17221/33/2012-PSE

14. A.I. Ermakov, Methods of Biochemical Research of Plants, 430 (Leningrad: Agropromizdat, 1987)

15. Z.A. Sedova, V.G. Leonchenko, A.I. Astakhov, Program and methods of fruit, berry and nut crop breeding, 160-167 (1999)

16. S. D. Aitzhanova, Dissertation for the degree of Doctor of Agricultural Sciences, 398 (2002)

17. N.I. Saveliev, A.N. Yushkov, A.S. Zemisov, A.V. Prokhorov, Gardening and viticulture 2, 20-21. (2004)

18. M.A. Makarkin, Dissertation for the degree of Doctor of Agricultural Sciences, 479 (2009) 